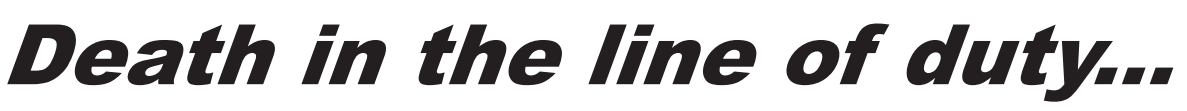

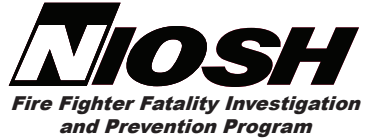

A summary of a NIOSH fire fighter fatality investigation

May, 2014

\section{Captain Suffers Fatal Heart Attack During Fire Control Training - North Carolina}

\section{Executive Summary}

On October 14, 2013, a 48-year-old male career fire department Captain was an instructor with the fire department's (FD) 6-month fire fighter recruit program. After practice drills in the morning wearing station uniforms and six live fire drills wearing full turnout gear and self-contained breathing apparatus (SCBA), the Captain suggested taking a break. He and a co-instructor doffed their turnout coat and SCBA and walked across the training ground to obtain water. After drinking some water, they proceeded into the training building. The Captain entered the $\mathrm{SCBA}$ refill room to locate spare cylinders for the next drills. As the co-instructor entered the room, the Captain vomited and complained of chest pain. The co-instructor notified the other training captain as the Captain asked the co-instructor to call an ambulance. Oxygen equipment was retrieved, and oxygen was administered to the Captain as his vital signs were taken. The ambulance arrived a few minutes later just as the Captain became unresponsive. Cardiopulmonary resuscitation (CPR) was begun along with advanced life support (ALS) including 10 defibrillation attempts without a change in the Captain's clinical condition. After 43 minutes of resuscitation efforts at the scene, the paramedics notified medical control of the incident, and the attending physician pronounced the Captain dead at 1632 hours.
The death certificate completed by the county medical examiner and the autopsy report completed by the state medical examiner listed "coronary artery thrombus" as the cause of death. The autopsy report also listed "chronic ischemic heart disease" as a contributing factor. Given the Captain's previously unidentified coronary artery disease (CAD), NIOSH investigators concluded that the physical stress of the training probably triggered a coronary artery plaque rupture. The rupture likely caused a blood clot that occluded his coronary artery, causing a fatal heart attack.

It is unlikely that the following recommendations would have prevented the Captain's death; however, NIOSH makes the recommendations to address general safety and health issues and to prevent similar incidents in the future.

Include medical monitoring in rehabilitation programs.

Provide annual medical evaluations to all fire fighters in accordance with NFPA 1582, Standard on Comprehensive Occupational Medical Program for Fire Departments.

Discontinue routine screening chest $x$-rays for members unless clinically indicated. 


\section{Captain Suffers Fatal Heart Attack During Fire Control Training \\ - North Carolina}

The National Institute for Occupational Safety and Health (NIOSH), an institute within the Centers for Disease Control and Prevention (CDC), is the federal agency responsible for conducting research and making recommendations for the prevention of work-related injury and illness. In 1998, Congress appropriated funds to NIOSH to conduct a fire fighter initiative that resulted in the NIOSH "Fire Fighter Fatality Investigation and Prevention Program" which examines line-of-duty-deaths or on duty deaths of fire fighters to assist fire departments, fire fighters, the fire service and others to prevent similar fire fighter deaths in the future. The agency does not enforce compliance with State or Federal occupational safety and health standards and does not determine fault or assign blame. Participation of fire departments and individuals in NIOSH investigations is voluntary. Under its program, NIOSH investigators interview persons with knowledge of the incident who agree to be interviewed and review available records to develop a description of the conditions and circumstances leading to the death(s). Interviewees are not asked to sign sworn statements and interviews are not recorded. The agency's reports do not name the victim, the fire department or those interviewed. The NIOSH report's summary of the conditions and circumstances surrounding the fatality is intended to provide context to the agency's recommendations and is not intended to be definitive for purposes of determining any claim or benefit. For further information, visit the program website at www.cdc.gov/niosh/fire or call toll free 1-800-CDC-INFO (1-800-232-4636). 


\section{Captain Suffers Fatal Heart Attack During Fire Control Training - North Carolina}

\section{Introduction \& Methods}

On October 14, 2013, a 48-year-old male career Captain suffered a fatal heart attack while instructing a fire fighter recruit class in live fire training. NIOSH was notified of the fatality by the U.S. Fire Administration on October 18, 2013. NIOSH contacted the affected FD on October 22,2013 , to gather additional information and on October 28, 2013, to initiate the investigation. On November 4, 2013, a safety and occupational health specialist from the NIOSH Fire Fighter Fatality Prevention and Investigation Program investigated the incident.

During the investigation, NIOSH personnel interviewed the following people:

- Fire chief

- Deputy Fire Chief for Safety \& Logistics

- Deputy chief for administration

- Deputy chief for operations and training

- Training academy director

NIOSH personnel reviewed the following documents:

- FD standard operating procedures

- FD annual report for 2012

- Emergency medical service (ambulance) report

- Death certificate

- Autopsy report

\section{Investigative Results}

Training Description. On October 14, 2013, the FD scheduled the live fire training as part of the FD's 6-month recruit training program. The scheduled training addressed the practical skill component of the multi-part fire control training [NFPA 2013a].

1. Interior fire fighting

2. Exterior fire fighting

3. Hidden fire

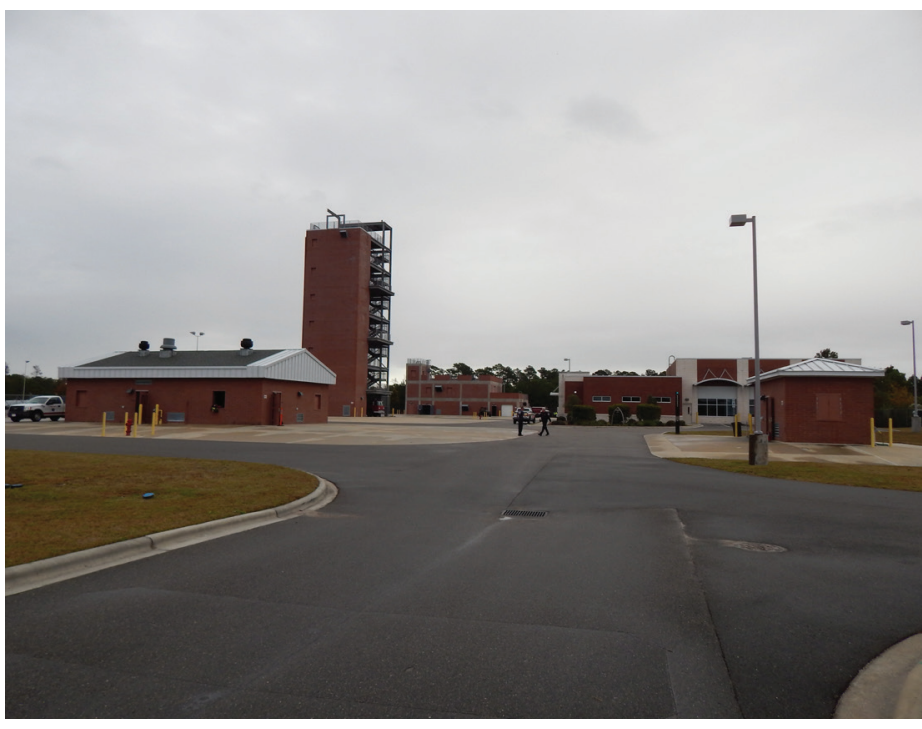

Photograph 1. The community college fire/rescue/emergency management training center. Photo by NIOSH

4. Combustible liquids

5. Attic/elevated locations

6 . Below grade areas

7. Flammable gas cylinder fire fighting

8. Ground cover fire fighting

The training was held at the community college fire/rescue/emergency management training center (Photograph 1).

Building Description. The commercial burn building was a two-story class II structure measuring 40 feet by 80 feet and constructed of noncombustible and limited combustible materials (Photograph 2). The building was equipped with a class I dry standpipe system in the northwest stairwell. A burn room equipped with one Fireblast LP gas-fueled live fire training prop was located on the first and second floors. The second floor burn room also had a flashover feature above the main prop. Those rooms were the only areas within the structure where actual fire conditions were initiated. 


\section{Captain Suffers Fatal Heart Attack During Fire Control Training - North Carolina}

\section{Investigative Results (cont.)}

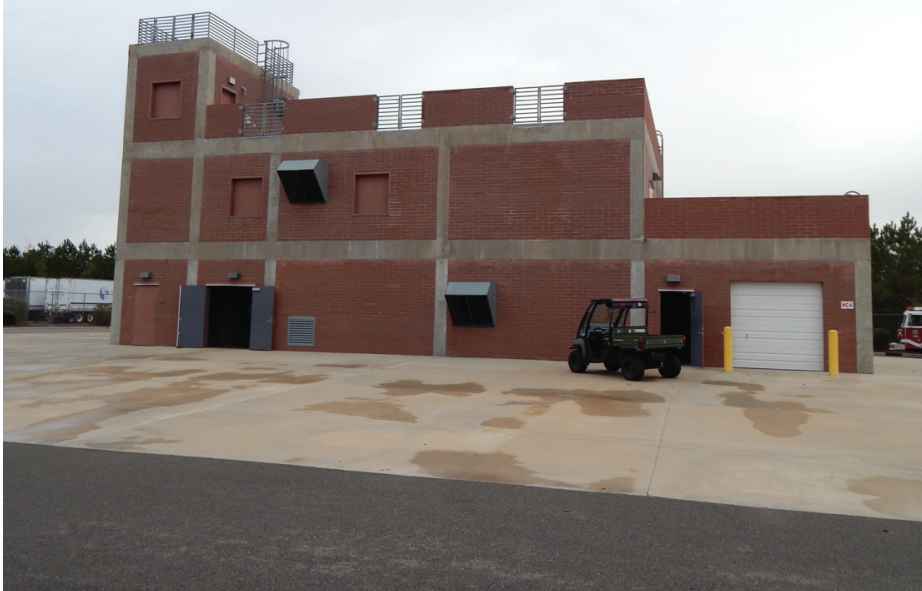

Photograph 2. The commercial burn building. Photo by NIOSH

Incident. Instructors arrived at about 0900 hours to set up the course. Four instructors (two from the county [including the Captain] and two from the city) and 20 cadets ( 8 county and 12 city) were present. Weather conditions during the day included a high temperature of 75 degrees Fahrenheit $\left({ }^{\circ} \mathrm{F}\right)$ and relative humidity of $71 \%$ [NOAA 2013].

The recruits assigned to the Captain and his co-instructor were split into two teams of four personnel. The initial drill included the deployment of an uncharged $2 \frac{1}{2}$-inch preconnected hoseline to the third floor. Both instructors observed and provided instruction during this evolution. Both teams conducted the evolution separately without incident.

The next series of evolutions involved charging the stairwell with smoke and advancing a charged $2 \frac{1}{2}$-inch preconnected hoseline. The Captain was assigned to the engineer's position at the fire engine, a role that did not involve a lot of physical exertion. Three squads rotated for a total of 12 evolutions taking approximately 60 minutes.
Personnel then broke equipment down and took a lunch break (1130 hours).

Training resumed at about 1315 hours. The Captain and his co-instructor were assigned to the live fire attacks on the second floor of the commercial building. The recruits were split into three teams of three each and briefed on the drill. The Captain, wearing full turnout gear and SCBA (on-air) operated the fire prop on the second floor, and his co-instructor oversaw fire attack applications. Each team remained on the attack line until each team member rotated to the nozzle position. The ambient temperature on the second floor was approximately $100^{\circ} \mathrm{F}$; the fire prop room reached approximately $400^{\circ} \mathrm{F}$. After each team rotated through the drill, the instructors took a break as the squads rotated from the previous station. When the next squad arrived, the Captain and the co-instructor switched positions with the Captain assuming fire attack. This evolution took approximately 2 hours. Upon completion, the Captain advised the two instructors to take a break, and they exited the building. Both instructors doffed their SCBAs and turnout coats, walked to the FD van, and hydrated with water. During the break the Captain reported vomiting, but wanted to continue with the training.

After a 10-minute break, the Captain entered the cascade room to refill the air cylinders for their next evolution (Photograph 3). While refilling the bottles, the Captain began vomiting again and reported "a little chest pain as well." After notifying the other instructors, the co-instructor found the Captain on his hands and knees stating that his chest pain had increased; he asked for an ambulance to be called (1538 hours). 


\section{Captain Suffers Fatal Heart Attack During Fire Control Training - North Carolina}

\section{Investigative Results (cont.)}

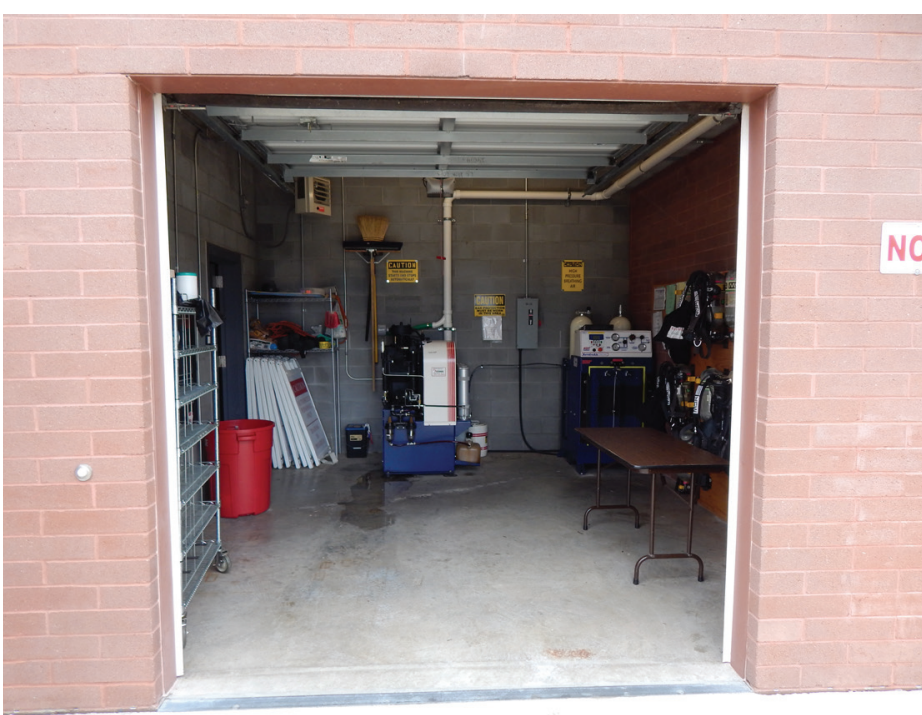

Photograph 3. Cascade room in the commercial burn building. Photo by $\mathrm{NIOSH}$

The co-instructor obtained oxygen equipment and an automated external defibrillator from the Captain's vehicle. Oxygen was administered via non-rebreather mask. His vital signs showed a blood pressure of 100 millimeters of mercury systolic, heart rate of 120 beats per minute, respiration rate of 20 breaths per minute, and a blood glucose reading of 110 milligrams per deciliter.

The ambulance arrived at 1548 hours. Cardiac monitoring revealed ventricular tachycardia. The Captain mentioned he was going to vomit again, became tense, and then became unresponsive, with no pulse or respirations. CPR was begun as the cardiac monitor revealed ventricular fibrillation. One shock was administered as an intraosseus line was placed. Cardiac resuscitation medications were administered; defibrillation was attempted nine times. After two unsuccessful intubation attempts, a third attempt was successful with tube placement verified by capnography [Neumar et al. 2010]. ALS continued for 27 minutes when the Captain briefly regained a pulse ( 40 beats per minute, weak and thready). Within a minute, his pulse was lost. CPR and ALS were continued without positive change for an additional 16 minutes. At 1632 hours, paramedics advised medical control that the resuscitation efforts were not producing positive change. The attending physician advised paramedics to cease resuscitation efforts and declared the Captain dead.

Medical Findings. The death certificate, completed by the county medical examiner, and the autopsy report, completed by the state medical examiner listed "coronary artery thrombus" as the cause of death. The autopsy report also listed "chronic ischemic heart disease" as a contributing factor. Cardiac findings showed left ventricular hypertrophy and focal moderate CAD (Appendix A).

The Captain was 71 inches tall and weighed 175 pounds at his last medical evaluation (September 2013), giving him a normal body mass index of 24.4 kilograms per meters squared [CDC 2011]. According to medical records, the Captain's only risk factor for coronary heart disease (CHD) was high blood low density lipoprotein (LDL), which was diagnosed in 2004. He was not prescribed a cholesterol-lowering medication but the FD contract physician recommended follow-up by his primary care physician. The Captain underwent an exercise stress test (EST) in 2010 during his annual FD medical evaluation. He exercised for 12 minutes on the Bruce protocol, achieving 13.5 metabolic equivalents and $100 \%$ of his maximal predicted heart rate with no evidence of ischemia. The Captain never complained of cardiac symptoms.

The Captain passed his physical fitness test in March 2013 with a time of 5 minutes and achieved a VO2max level of 45.5 milligrams/kilogram/minute. He passed his annual FD medical evaluation in September 2013. 


\section{Captain Suffers Fatal Heart Attack During Fire Control Training - North Carolina}

\section{Description of the Fire Department}

At the time of the NIOSH investigation, the FD consisted of eight fire stations with 152 career and 32 volunteer uniformed personnel. The FD served 86,000 residents in a geographic area of 147 square miles. In 2012, the FD responded to 4,881 incidents: 304 fire calls, 2,819 emergency medical/rescue calls, and 1,758 other calls including hazardous conditions, false alarms, and service calls.

\section{Membership and Training. The FD requires new} career fire fighter applicants to be 18 years of age to be a fire fighter and 21 years of age to be a fire fighter/apparatus operator; be a high school graduate or have the equivalent certificate; have a valid state driver's license; and pass a candidate physical fitness test (Appendix B) and an interview before being offered a conditional job offer. The potential new hire then must pass criminal/driver background checks, a preplacement medical evaluation (contents described below), and a drug screen. The new member then begins the 6-month fire training academy to become trained as a fire fighter II, emergency vehicle driver, technical and vehicle rescue, and emergency medical technician. The new member works 24-hours on duty/24-hours off duty for three shifts, then is off duty for 4 days. The Captain was certified as a fire fighter 2, fire officer 3 , emergency vehicle driver, fire inspector, fire instructor 2, rescue technician, arson investigator, in structural collapse, in water rescue, and in hazardous materials. He worked Monday -Friday from 0730 hours to 1600 hours and had 10 years of fire fighting experience with this fire department.

Preplacement and Periodic Medical Evaluations. The FD requires preplacement medical evaluations for all applicants. Components of this evaluation include the following:
- Complete medical history

- Physical examination (including vital signs - height, weight, blood pressure, pulse, and respirations)

- Vision test (acuity, color, peripheral fields, and depth perception)

- Audiogram

- Spirometry

- Electrocardiogram (EKG)

- Urinalysis

- Blood tests (complete blood count, lipids)

- Chest x-ray (baseline and every 4 years)

The medical evaluations are performed by a FD-contracted physician. The physician makes a determination regarding medical clearance for fire fighting duties and forwards this decision to the FD. The Captain had an annual medical evaluation in September 2013, 1 month before he died. Although he was referred to his primary care physician for follow-up for his elevated low density lipoprotein blood level, no other medical problems were identified; he was cleared for unrestricted duty as a fire fighter.

Annual medical evaluations are required for members. The components are the same as the preplacement medical evaluation. Medical clearance to wear a respirator is required for suppression fire fighters. Members injured on duty or who become ill and miss work must be evaluated by the FD-contracted physician who forwards a determination for return to duty to the FD. Members who have a temporary disability and are not capable of performing their regular job duties are placed on limited duty. The member must obtain a fit for duty evaluation from the FDcontracted physician. 


\section{Captain Suffers Fatal Heart Attack During Fire Control Training - North Carolina}

\section{Description of the FD (cont.)}

Health and Wellness Programs. The FD has a mandatory wellness/fitness program, and exercise equipment is available in the fire stations. The FD has a peer fitness trainer on staff to prescribe specific exercise programs for individual members and general programs for the entire FD. The trainer also assists those on medical-related limited duty to ensure the member is returned to duty in compliance with NFPA 1582 [NFPA 2013b]. An annual job performance physical ability test is required for all members (Appendix C). The FD also offers annual job performance physical fitness assessments (Appendix D). The Captain participated in a prescribed fitness/ wellness program 4 days each week.

\section{Discussion}

Atherosclerotic Coronary Heart Disease. In the United States, atherosclerotic CHD is the most common risk factor for cardiac arrest and sudden cardiac death [Meyerburg and Castellanos 2008]. Risk factors for its development include age older than 45, male gender, family history of CAD, smoking, high blood pressure, high blood cholesterol, obesity/physical inactivity, and diabetes [NHLBI 2012; AHA 2014]. The Captain had one modifiable CHD risk factor (high blood LDL) and had single vessel moderate CHD on autopsy. The Captain also had microscopic evidence of an old (remote) heart attack at autopsy, although he reported no previous episodes of chest pain (angina) and had normal resting EKGs.

The narrowing of the coronary arteries by atherosclerotic plaques occurs over many years, typically decades [Libby 2008]. However, the growth of these plaques probably occurs in a nonlinear, often abrupt fashion [Shah 1997]. Heart attacks (myocardial infarctions) typically occur with the sudden development of complete blockage (occlusion) in one or more coronary arteries that have not developed a collateral blood supply [Fuster et al. 1992]. This sudden blockage is primarily due to blood clots (thrombosis) forming on top of atherosclerotic plaques.

Establishing a recent (acute) heart attack requires any of the following: characteristic EKG changes, elevated cardiac enzymes, or coronary artery thrombus. The Captain had an intracoronary thrombus identified at autopsy, which confirms a heart attack.

Epidemiologic studies have found that heavy physical exertion sometimes immediately precedes and triggers the onset of acute heart attacks and sudden cardiac death [Mittleman et al. 1993; Willich et al. 1993; Albert et al. 2000]. Heart attacks in fire fighters have been associated with alarm response, fire suppression, and heavy exertion during training (including physical fitness training) [Kales et al. 2003; Kales et al. 2007; NIOSH 2007]. The Captain had operated the fire prop and instructed the fire attack evolutions while wearing full turnout gear and SCBA in a hot environment. This activity expended about 8 metabolic equivalents, which is considered moderate physical activity [Gledhill and Jamnik 1992; Ainsworth et al. 2011].

\section{Occupational Medical Standards for Structural} Fire Fighters and Exercise Stress Test. To reduce the risk of sudden cardiac arrest or other incapacitating medical conditions among fire fighters, the National Fire Protection Association (NFPA) developed NFPA 1582, Standard on Comprehensive Occupational Medical 


\section{Captain Suffers Fatal Heart Attack During Fire Control Training - North Carolina}

\section{Discussion (cont.)}

Program for Fire Departments [NFPA 2013b]. This voluntary industry standard provides the components of a preplacement and annual medical evaluation and medical fitness for duty criteria. The Captain's underlying cardiac abnormalities were not identified until his autopsy. Recommendations for ESTs on asymptomatic individuals without known heart disease are varied. Based on the Captain's age and high LDL in 2011-2013, the NFPA, the American College of Cardiology/American Heart Association (ACC/AHA), and the United States Preventive Services Task Force (USPSTF) would not have recommended a more recent symptom limiting EST. The following paragraphs summarize the positions of widely recognized organizations on this topic.

NFPA 1582, a voluntary industry standard, recommends an EST performed "as clinically indicated by history or symptoms" and refers the reader to Appendix A [NFPA 2013b]. Items in Appendix A are not standard requirements, but are provided for "informational purposes only." Appendix A recommends using submaximal (85\% of predicted heart rate) stress tests as a screening tool to evaluate a fire fighter's aerobic capacity. Maximal (i.e., symptom-limiting) stress tests with imaging should be used for fire fighters with the following conditions:

- abnormal screening submaximal tests

- cardiac symptoms

- known CAD

- one or more risk factors for CAD (in men older than 45 and women older than 55)

Negative stress tests should be repeated as clinically indicated or at least every 2 to 5 years.
Risk factors are defined as hypercholesterolemia (total cholesterol greater than 240 milligrams per deciliter), hypertension (diastolic blood pressure greater than 90 millimeters of mercury), smoking, diabetes mellitus, or family history of premature CAD (heart attack or sudden cardiac death in a first-degree relative less than 60 years old).

The ACC/AHA has also published exercise testing guidelines [Gibbons et al. 2002]. The ACC/AHA guideline states that the evidence to conduct stress tests in asymptomatic individuals is "less well established" (Class IIb) for the following groups:

- persons with multiple risk factors (defined similarly to those listed by the NFPA)

- asymptomatic men older than 45 years and women older than 55 years:

- who are sedentary and plan to start vigorous exercise

o who are involved in occupations in which impairment might jeopardize public safety (e.g., fire fighters)

$\circ$ who are at high risk for CAD due to other diseases (e.g., peripheral vascular disease and chronic renal failure)

The U.S. Department of Transportation provides guidance for those seeking medical certification for a commercial driver's license. An expert medical panel recommended exercise tolerance tests (stress tests) for asymptomatic "high risk" drivers [Blumenthal et al. 2007]. The panel defines high risk drivers as those with any of the following:

- diabetes mellitus

- peripheral vascular disease

- age 45 and above with multiple risk factors for CHD

- Framingham risk score predicting a 20\% CHD event risk over the next 10 years 


\section{Captain Suffers Fatal Heart Attack During Fire Control Training - North Carolina}

\section{Discussion (cont.)}

The U.S. Preventive Services Task Force (USPSTF) does not recommend stress tests for asymptomatic individuals at low risk for coronary heart disease events. For individuals at increased risk for CHD events, the USPSTF found "insufficient evidence to recommend for or against routine screening with EKG, exercise tolerance test, or electron beam computerized tomography scanning...." Rather, they recommend the diagnosis and treatment of modifiable risk factors (hypertension, high cholesterol, smoking, and diabetes) [USPSTF 2004]. The USPSTF does note that "For people in certain occupations, such as pilots, and heavy equipment operators (for whom sudden incapacitation or sudden death may endanger the safety of others), consideration other than the health benefit to the individual patient may influence the decision to screen for coronary heart disease."

In summary, the Captain had an acute heart attack despite being asymptomatic, having minimal CHD risk factors, and having a negative maximal EST 3 years before his death.

\section{Recommendations}

It is unlikely the following recommendations would have prevented the Captain's death; however, NIOSH makes the recommendations to address general safety and health issues and to prevent similar incidents in the future.

\section{Recommendation \#1: Include medical monitoring in the rehabilitation programs.}

A model rehabilitation program can be found in NFPA 1584, Standard on the Rehabilitation Process for Members During Emergency Operations and Training Exercises [NFPA
2008]. Medical monitoring should be part of any rehabilitation program. This would consist of evaluating the symptoms, signs, and vital signs of personnel upon entry to, and discharge from, the rehabilitation program. These findings should be recorded and maintained. Symptomatic members or members with abnormal findings should receive medical monitoring and/or be evaluated for potential transport to the ED. If medical care is given, a medical report should be completed and maintained.

\section{Recommendation \#2: Provide annual} medical evaluations to all fire fighters in accordance with NFPA 1582, Standard on Comprehensive Occupational Medical Program for Fire Departments.

Guidance regarding the content and frequency of these medical evaluations can be found in NFPA 1582 and in the International Association of Fire Fighters (IAFF)/International Association of Fire Chiefs (IAFC) Fire Service Joint Labor Management Wellness/Fitness Initiative [IAFF, IAFC 2008; NFPA 2013b]. These evaluations are performed to determine fire fighters' medical ability to perform duties without presenting a significant risk to the safety and health of themselves or others. While the FD is following most of the components of NFPA 1582, they are not conducting stress tests for fire fighters at increased risk of CHD. The FD is not legally required to follow the NFPA standard or the IAFF/IAFC guideline.

Recommendation \#3: Discontinue routine screening chest $x$-rays for members, unless clinically indicated. 


\section{Captain Suffers Fatal Heart Attack During Fire Control Training - North Carolina}

\section{Recommendations (cont.)}

Chest x-rays are conducted every 4 years as part of the FD's annual medical assessment. According to NFPA 1582, "chest x-rays shall include an initial baseline and shall be repeated every 5 years or as medically indicated" [NFPA 20013b]. Doing chest x-rays every 4 years, or even every 5 years, exposes members to unnecessary radiation and represents an unnecessary expense for the FD. Routine screening chest $\mathrm{x}$-rays are not recommended by the OSHA hazardous materials standard, unless clinically indicated (e.g., respiratory symptoms) [NIOSH 1985; CFR 2012].

\section{References}

AHA (American Heart Association) [2014]. Understand your risk of heart attack. Dallas, TX: American Heart Association. [http://www. heart.org/HEARTORG/Conditions/HeartAttack/ UnderstandYourRiskofHeartAttack/UnderstandYour-Risk-of-Heart-Attack UCM 002040 Article.jsp]. Date accessed: May 2014.

Ainsworth BE, Haskell WL, Herrmann SD, Meckes N, Bassett DR Jr, Tudor-Locke C, Greer JL, Vezina J, Whitt-Glover MC, Leon AS [2011]. Compendium of physical activities: a second update of codes and MET values. Med Sci Sports Exerc 43(8):1575-1581.

Albert CM, Mittleman MA, Chae CU, Lee IM, Hennekens CH, Manson JE [2000]. Triggering of sudden death from cardiac causes by vigorous exertion. N Engl J Med 343(19):1355-1361.
Blumenthal RS, Epstein AE, Kerber RE [2007]. Expert panel recommendations. Cardiovascular disease and commercial motor vehicle driver safety. [http://www.mrb.fmcsa.dot.gov/documents/CVD Commentary.pdf]. Date accessed: May 2014.

CDC (Centers for Disease Control and Prevention) [2011]. Assessing your weight. [http:// www.cdc.gov/healthyweight/assessing/index.

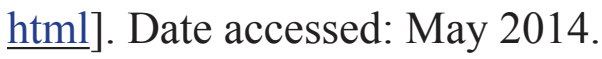

CFR [2012]. Code of Federal Regulations [29 CFR 1910.120]. OSHA standards interpretation. Medi $\neg$ cal surveillance requirements for hazmat work $\neg$ ers. Washington, DC: U.S. Government Printing Office, Office of the Federal Register. [http:/www.osha.gov/pls/oshaweb/owadisp.show document?p table=INTERPRETATIONS\&p

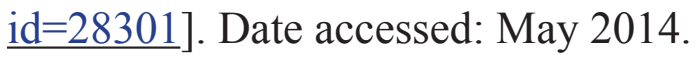

Fuster V, Badimon L, Badimon JJ, Chesebro JH [1992]. The pathogenesis of coronary artery disease and the acute coronary syndromes. N Engl J Med 326(4):242-250.

Gibbons RJ, Balady GJ, Bricker JT, Chaitman BR, Fletcher GF, Froelicher VF, Mark DB, McCallister BD, Mooss AN, O’Reilly MG, Winters WL Jr., Antman EM, Alpert JS, Faxon DP, Fuster V, Gregoratos G, Hiratzka LF, Jacobs AK, Russell RO, Smith SC Jr [2002]. ACC/AHA 2002 guideline update for exercise testing: a report of the American College of Cardiology/ American Heart Association Task Force on Practice Guidelines. Circulation 106(14):1883-1892.

Gledhill N, Jamnik VK [1992]. Characterization of the physical demands of firefighting. Can J Spt Sci 17(3):207-213. 


\section{Captain Suffers Fatal Heart Attack During Fire Control Training - North Carolina}

\section{References (cont.)}

IAFF, IAFC [2008]. The fire service joint labor management wellness/fitness initiative. $3 \mathrm{rd}$ ed. Washington, DC: International Association of Fire Fighters, International Association of Fire Chiefs.

Kales SN, Soteriades ES, Christoudias SG, Christiani DC [2003]. Firefighters and on-duty deaths from coronary heart disease: a case control study. Environ health: a global access science source. 2:14. [http://www.ehjournal.net/ content/2/1/14]. Date accessed: May 2014.

Kales SN, Soteriades ES, Christophi CA, Christiani DC [2007]. Emergency duties and deaths from heart disease among fire fighters in the United States. N Engl J Med 356(12):12071215.

Libby P [2008]. The pathogenesis, prevention, and treatment of atherosclerosis. In: Fauci AS, Braunwald E, Kasper DL, Hauser SL, Longo DL, Jameson JL, Loscalzo J, eds. Harrison's principles of internal medicine. 17th ed. New York:

McGraw-Hill, pp. 1501-1509.

Meyerburg RJ, Castellanos A [2008].

Cardiovascular collapse, cardiac arrest, and sudden cardiac death. In: Fauci AS, Braunwald E, Kasper DL, Hauser SL, Longo DL, Jameson JL, Loscalzo J, eds. Harrison's principles of internal medicine. 17th ed. New York: McGraw-Hill, pp. 1707-1713.

Mittleman MA, Maclure M, Tofler GH, Sherwood JB, Goldberg RJ, Muller JE [1993]. Triggering of acute myocardial infarction by heavy physical exertion. N Engl J Med 329(23):1677-1683.
NFPA [2008]. Standard on the rehabilitation process for members during emergency operations and training exercises. Quincy, MA: National Fire Protection Association. NFPA 1584.

NFPA [2013a]. Standard for fire fighter professional qualifications. Quincy, MA: National Fire Protection Association. NFPA 1001.

NFPA [2013b]. Standard on comprehensive occupational medical program for fire departments. Quincy, MA: National Fire Protection Association. NFPA 1582.

NHLBI [2012]. Who is at risk for coronary artery disease? National Heart, Lung, and Blood Institute. [http://www.nhlbi.nih.gov/health/ health-topics/topics/cad/atrisk.html]. Date accessed: May 2014.

NIOSH [1985]. Occupational safety and health guidance manual for hazardous waste site activities. Cincinnati, OH: U.S. Department of Health and Human Services, Public Health Service, Centers for Disease Control, National Institute for Occupational Safety and Health, DHHS (NIOSH) Publication No. 85-115. [http://www. cdc.gov/niosh/pdfs/85-115-a.pdf]. Date accessed: May 2014.

NIOSH [2007]. NIOSH alert: preventing fire fighter fatalities due to heart attacks and other sudden cardiovascular events. [http://www. cdc.gov/niosh/docs/2007-133/]. Cincinnati, OH: U.S. Department of Health and Human Services, Centers for Disease Control and Prevention, National Institute for Occupational Safety and Health, DHHS (NIOSH) Publication No. 2007-133. 


\section{Captain Suffers Fatal Heart Attack During Fire Control Training - North Carolina}

\section{References (cont.)}

NOAA [2013]. Quality controlled local climatological data: (final). Hourly observations table, Wilmington International Airport October 14, 2013. National Oceanic and Atmospheric Administration. [http://cdo.ncdc.noaa.gov/qclcd/ QCLCD]. Date accessed: May 2014.

Neumar RW, Otto CW, Link MS, Kronick SL, Shuster M, Callaway CW, Kudenchuk PJ, Ornato JP, McNally B, Silvers SM, Passman RS, White RD, Hess EP, Tang W, Davis D, Sinz E, Morrison LJ [2010]. Part 8: Adult advanced cardiovascular life support. 2010 American Heart Association Guidelines for cardiopulmonary resuscitation and emergency cardiovascular care. Dallas, TX: American Heart Association.

Shah PK [1997]. Plaque disruption and coronary thrombosis: new insight into pathogenesis and prevention. Clin Cardiol 20(11 Suppl2):II-38-44.

USPSTF [2004]. U.S. Prevention Services Task Force. Screening for coronary heart disease: Recommendation Statement. Ann Intern Med 140(7):569-572.

Willich SN, Lewis M, Lowel H, Arntz HR, Schubert F, Schroder R [1993]. Physical exertion as a trigger of acute myocardial infarction. $\mathrm{N}$ Engl J Med 329(23):1684-1690.

\section{Investigator Information}

This incident was investigated by the NIOSH Fire Fighter Fatality Investigation and Prevention Program, Cardiovascular Disease Component in Cincinnati, Ohio. Mr. Tommy Baldwin (MS) led the investigation and co-authored the report. Mr. Baldwin is a Safety and Occupational Health Specialist, a National Association of Fire Investigators (NAFI) Certified Fire and Explosion Investigator, an International Fire Service Accreditation Congress (IFSAC) Certified Fire Officer I, and a former Fire Chief and Emergency Medical Technician. Dr. Thomas Hales (MD, MPH) provided medical consultation and co-authored the report. Dr. Hales is a member of the NFPA Technical Committee on Occupational Safety and Heath, and Vice-Chair of the Public Safety Medicine Section of the American College of Occupational and Environmental Medicine (ACOEM). 


\section{Captain Suffers Fatal Heart Attack During Fire Control Training - North Carolina}

\section{Appendix A}

\section{Pertinent Autopsy Findings}

- Coronary artery atherosclerosis

- Coronary artery thrombus occluding the left anterior descending coronary artery

- Moderate $(60 \%)$ focal narrowing at other points of the left anterior descending coronary artery

- No focal narrowing of the right coronary artery

- No focal narrowing of the left circumflex coronary artery

- Microscopic: areas of patchy fibrosis with hemosiderin-laden macrophages and granulation tissue in the posterior left ventricle consistent with patchy ischemic injury several weeks old, scarring in the septum consistent with a remote (old) ischemic event, and patchy interstitial fibrosis

- Left ventricle thickened (1.3 centimeter $[\mathrm{cm}])$

- Normal at autopsy is $0.76-0.88 \mathrm{~cm}$ [Colucci and Braunwald 1997]

- Normal by echocardiographic measurement is $0.6-1.0 \mathrm{~cm}$ [Connolly and $\mathrm{Oh} 2012$ ]

- Normal cardiac valves

- No evidence of a pulmonary embolus (blood clot in the lung arteries)

- Blood tests for drugs and alcohol were negative.

\section{Appendix B}

\section{Candidate Physical Fitness Test}

1. Sit ups. Maximum number in 30 seconds. Minimum of 16.

2. Balance test. Number of steps before deviating from line. Add best three of five trials. Maximum 10 steps per trial.

3. Hip flexibility. Reaching at least 15 inches.

4. Push-ups. 30-second time limit. Minimum of 10.

5. Vertical jump. Best of two trials. Minimum of 14 inches.

6. Fire fighter ability course.

a. Hose carry. Carry 100-foot high rise pack to the third floor.

b. Hose hoist. Raise 3-inch donut roll from ground by rope. Walk down stairs to ladder raise.

c. Ladder raise. One-man carry and placement. Flat wall raise. Upon completion, walk to hose drag.

d. Charged hose drag. Advance 75 -foot 13/4inch charged hoseline. Place nozzle at the manikin drag.

e. Manikin drag. Drag the 165-pound manikin 75 feet.

\section{References}

Colucci WS, Braunwald E [1997].

Pathophysiology of heart failure. In: Braunwald, ed. Heart disease. 5th ed. Philadelphia, PA: W.B. Saunders Company, p. 401.

Connolly HM, Oh JK [2012]. Echocardiography. In: Bonow RO, Mann DL, Zipes DP, Libby P, Braunwald E, eds. Heart disease: a text of cardiovascular medicine. 9th ed. Vol. 1. Philadelphia, PA: Elsevier Saunders, p. 216. 


\section{Captain Suffers Fatal Heart Attack During Fire Control Training - North Carolina}

\section{Appendix $\mathbf{C}$}

\section{Job Performance Physical Ability Test}

Any member who fails to successfully complete the test will be required to undergo further physical fitness evaluation and to participate in a strict program for fitness improvement. Failure to participate in the program or repeated failure of the test will be an indication that the member can no longer perform the essential job functions and may result in dismissal.

During the entire test, the participant will wear full structural turnout gear including SCBA. Time runs continuously from start to finish. No running allowed. The passing time for the test is 15 minutes and 30 seconds or less. One by one, members begin at station one and move to the next station without stopping.

Station Number, Description

1. Pull a bundle of dry hose line (200 feet of 13/4-inch hoseline) from the truck shelf and place on ground. 2. Pull a separate dry hose line (same size) 75 feet. Walk back to truck.

3. Remove a 16-foot ladder from the extended ladder bracket of the truck. Carry the ladder and place it on the side of the drill tower. Raise ladder to wall. Check for proper placement. Walk to stairwell of drill tower. 4. Pick up a high-rise pack at base of stairwell (100-foot section of $13 / 4$-inch hoseline formed into a "soft pack"). While carrying high-rise pack, climb stairs to the fourth floor of the drill tower. Drop the high-rise pack in the breezeway. Begin breathing from SCBA (remain on air for remainder of test). 5. Go to ground floor utilizing the interior stairwell and exit tower to the right. Advance to nozzle end of charged hose section (50-feet of 13/4-inch charged hoseline). Crawl around the building dragging charged hose section, making your way to the cones simulating a doorway. Upon reaching doorway, pull the remainder of hose section across event finish line while remaining on at least one knee.

6. Go to the commercial burn building and climb a fixed pre-positioned ladder to the second floor area of the commercial burn building.

7. Make your way back down the exterior stairs on the right side to the ground, then to the Keiser machine.

8. Mount the Keiser machine by standing over the sled straddling the I-beam; begin striking the I-beam until the I-beam passes the \#10. This will be accomplished by using an 8-pound sledge hammer with an overhead swing.

Failure to achieve a passing score on the test will result in the following steps:

1. Immediate removal from response duty assignments.

2. A medical examination will result in proceeding to lack of clearance and will be dealt with on an individual basis as a fit for duty issue.

3. Assignment to limited duty, under the supervision of the Resource and Risk Services Division Chief, for a period not to exceed 90 days. During this period, the individual will participate in an exercise regimen prescribed by the department. The member may choose to take the test at any time during the 90 days in order to return to full duty (if a passing score is achieved). Failure to successfully pass the test within the initial 45 days will result in a meeting with the Fire Chief to determine the employee is working toward this requirement. Failure to pass the test within 90 days of the original test may result in disciplinary action up to termination. 


\section{Captain Suffers Fatal Heart Attack During Fire Control Training - North Carolina}

\section{Appendix D}

\section{Annual Physical Fitness Assessments}

The Physical Fitness Assessment will be offered by the department annually. The design of the exam is to promote health and fitness to the members and to educate fire fighters in areas where they could improve their health and wellness. The results of the examination are collected and exercise programs and nutrition recommendations are provided to each member per their request. This assessment is not punitive.

The Physical Fitness Assessment consists of the following:

- Body composition (skin fold caliper evaluation)

- Aerobic capacity (treadmill)

- Strength (hand, arm, leg dynamometer)

- Or vertical jump (explosive power)

- Endurance (static plank, push-ups)

- Or alternate grip push-up

- Flexibility (modified sit and reach) 